\title{
THE MACHINE AGE OF
}
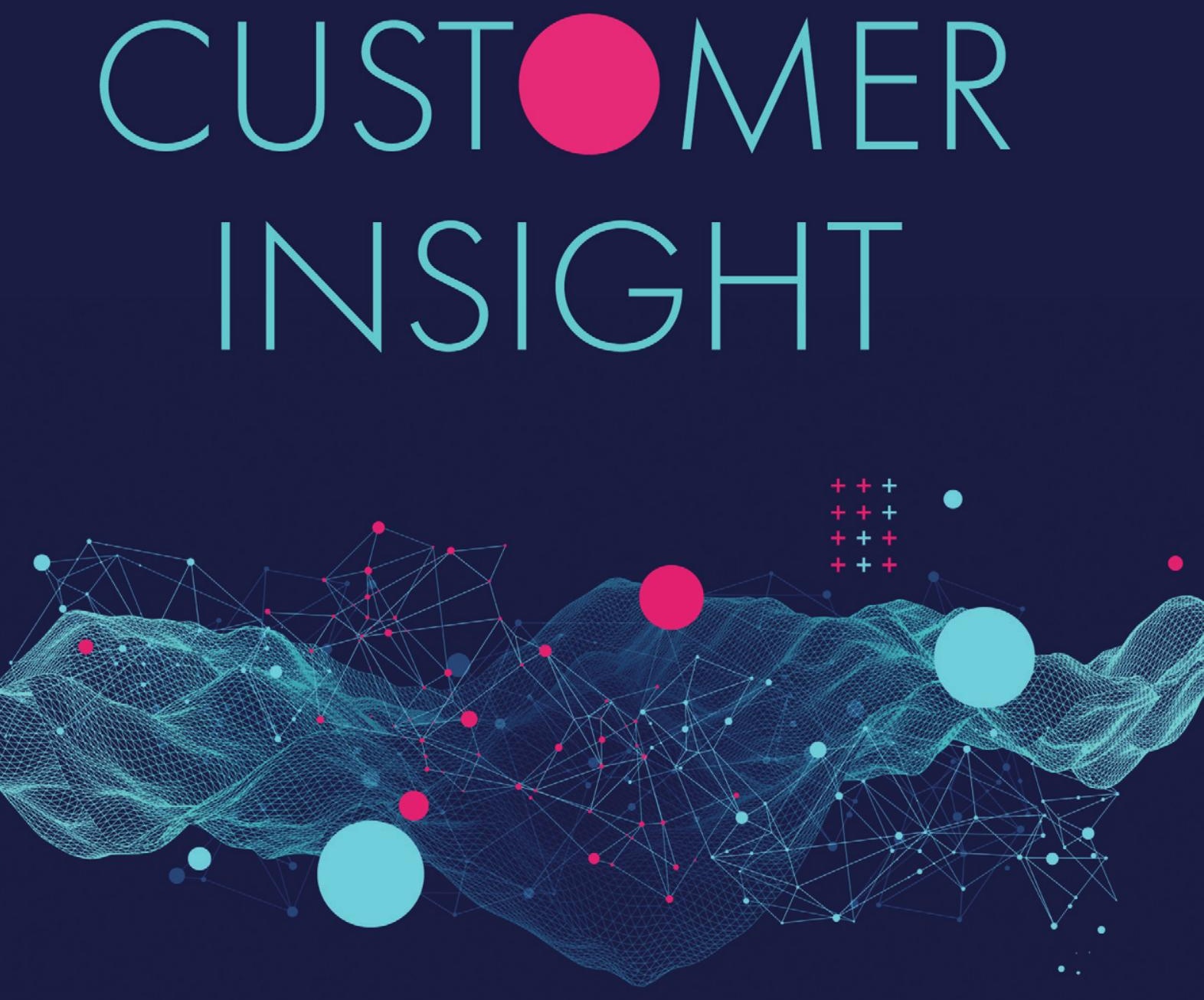

EDITORS

Martin Einhorn, Michael Löffler,

Emanuel de Bellis, Andreas Herrmann,

and Pia Burghartz 


\section{The Machine Age of Customer Insight}


This page intentionally left blank 


\section{The Machine Age of Customer Insight}

Edited by

\section{Dr. Martin Einhorn}

Director of Customer Evaluation and Analytics, Porsche AG, Germany

\section{Prof. Dr. Michael Löffler}

Vice President for Sales Planning and Strategy, Porsche AG, Germany

\section{Prof. Dr. Emanuel de Bellis}

Assistant Professor, University of Lausanne, Switzerland

\section{Prof. Dr. Andreas Herrmann}

Full Professor and Director, University of St. Gallen, Switzerland

\section{Pia Burghartz}

PhD Candidate and Research Associate, University of

St. Gallen, Switzerland

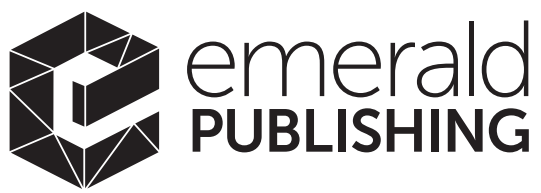

United Kingdom - North America Japan - India - Malaysia - China 
Emerald Publishing Limited

Howard House, Wagon Lane, Bingley BD16 1WA, UK

First edition 2021

Copyright @ 2021 Emerald Publishing Limited

\section{Reprints and permissions service}

Contact: permissions@emeraldinsight.com

No part of this book may be reproduced, stored in a retrieval system, transmitted in any form or by any means electronic, mechanical, photocopying, recording or otherwise without either the prior written permission of the publisher or a licence permitting restricted copying issued in the UK by The Copyright Licensing Agency and in the USA by The Copyright Clearance Center. Any opinions expressed in the chapters are those of the authors. Whilst Emerald makes every effort to ensure the quality and accuracy of its content, Emerald makes no representation implied or otherwise, as to the chapters' suitability and application and disclaims any warranties, express or implied, to their use.

\section{British Library Cataloguing in Publication Data}

A catalogue record for this book is available from the British Library

ISBN: 978-1-83909-697-6 (Print)

ISBN: 978-1-83909-694-5 (Online)

ISBN: 978-1-83909-696-9 (Epub) 


\section{Contents}

Introduction

Martin Einhorn, Michael Löffler, Emanuel de Bellis,

Andreas Herrmann, and Pia Burghartz

\section{Part 1 Transformation}

Chapter 1 Transformation of Customer Insights

Martin Einhorn and Michael Löffler

Chapter 2 Intelligent Applications in the Modern Sales

Organization

Gilberto Picareta, Eugenie Weissheim, and Martin Klöhn

Chapter 3 Voice and Facial Coding in Market Research

Niels Neudecker, Deepak Varma, David Wright, and Robert Powell

Chapter 4 Machine-Driven Content Marketing

Javiera M. Guedes, Akinbami Akinwale, and María Requemán Fontecha

Chapter 5 Leveraging Customer Insights with 5G

Marco Ottawa

\section{Part 2 Analytical Tools}

Chapter 6 Overview of Machine Learning Tools

Brett Lantz

Chapter 7 Neural Networks and Deep Learning

Hongming Wang, Ryszard Czerminski, and Andrew C. Jamieson

Chapter 8 Classification Using Decision Tree Ensembles 
Chapter 9 Text Analytics and Natural Language Processing 119 Ted Kwartler

Chapter 10 A Step-by-Step Guide for Data Scraping

Reto Hofstetter

\section{Part 3 Success Factors}

Chapter 11 Data Privacy: A Driver for Competitive Advantage

Timo Jakobi, Max von Grafenstein, and Thomas Schildhauer

Chapter 12 Data Collection: Welcome to the Experience Economy

Bruce Temkin

Chapter 13 Data Technology: Turning Business Data into Business Value

Irfan Khan

Chapter 14 Data Competitions: Crowdsourcing with Data Science Platforms

Jenny Lena Zimmermann

Chapter 15 Data Processing: KontoSensor as an Application of Predictive Analytics

Raimund Blache, Lars Fetzer, René Michel, and Tobias von Martens

Chapter 16 Data Visualization: The Power of Storytelling

Ted Frank

Index 


\section{Introduction}

\section{Martin Einhorn, ${ }^{1}$ Michael Löffler, ${ }^{2}$ Emanuel de Bellis, ${ }^{3}$ Andreas Herrmann, ${ }^{4}$ and Pia Burghartz ${ }^{5}$}

The upcoming machine age offers a unique opportunity to gain novel, in-depth customer insights and to unleash enormous potential in various business areas. The abundance of data and the pace of progress in transforming data into actionable knowledge affects

\footnotetext{
${ }^{1}$ Dr. Martin Einhorn is Director for Customer Evaluation and Analytics at Dr. Ing. h.c. F. Porsche AG and lecturer at Sigmund Freud University Vienna. Previously he worked as market and trend researcher with Audi AG. He received his Doctoral Degree from the University of St. Gallen where he was responsible for market research projects with large international retailers. He has a long record of research co-operations with several universities including projects on data privacy, decision making, psychology of mobility and autonomous driving, education in empirical research, and new ways of customer integration in innovation processes.

${ }^{2}$ Prof. Dr. Michael Löffler is Vice President for Sales Planning and Strategy at Dr. Ing. h.c. F. Porsche AG. He heads several departments responsible for sales strategy, organizational development, global training, and innovation at Porsche. Before assuming this role in 2018, he held various positions at Porsche, most recently as Vice President Customer Relations and Head of Marketing Planning. In addition, he has extensive and sound experience in the branded goods and consumer goods sector with a focus on consumer behavior and marketing strategy. Michael Löffler graduated in mathematical economics from the University of Karlsruhe, where he also obtained his doctorate in marketing.

${ }^{3}$ Prof. Dr. Emanuel de Bellis is Assistant Professor of Marketing at the University of Lausanne. In his research, Emanuel combines insights from behavioral science and technology to explore consumers' perception and use of autonomous products and other AI-based technologies. He has published in leading international journals such as the Journal of Marketing Research. Emanuel spent research visits at Columbia University in the USA, the University of British Columbia in Canada, and the Max Planck Institute for Human Development in Germany. He holds a PhD from the University of St. Gallen.

${ }^{4}$ Prof. Dr. Andreas Herrmann is Director for Marketing and Research Methods at the Institute for Customer Insight at the University of St. Gallen. Since September 2019 he is also Visiting Professor at the London School of Economics and Political Science (LSE). In his research, Andreas focuses particularly on Behavioral Economics and Brand Management. Andreas has published 15 books in areas such as digitization, market research, and empirical methods. He has also published more than 250 scientific papers in leading international journals such as the Journal of Marketing, the Journal of Marketing Research, and Harvard Business Review. He received his PhD from the Otto Beisheim School of Management (WHU).

${ }^{5}$ Pia Burghartz is a PhD candidate and research associate at the Institute for Customer Insight at the University of St. Gallen. She is involved in various projects with industry partners on autonomous driving and shared mobility. Her research focuses on consumers' perception and acceptance of autonomous technologies, as well as consumers' desire for uniqueness and conformity. Pia holds a master's degree in Law and Economics from the Erasmus University Rotterdam, the University of Hamburg, and Aix-Marseille University (M.Sc., LL.M.). She has several years of professional experience in marketing, mainly in the automotive, medical technology, and aviation industry.
} 
players across nearly all industries. This book offers a short pit stop in the race for customer insights and insight-based decision making through machine learning tools. It summarizes recent developments in business and academia, and offers readers proven practical guidance in what is about to become the new normal.

Outstanding authors from innovative firms and renowned universities provide a comprehensive overview of the transformation of customer insights, the tools needed to generate these insights, and the success factors to thrive in the new age. Their contributions underpin the key message: The machine age of customer insight requires wellfounded, data-based decision making, consistent execution and - more than ever continuous and fast learning. This book aims to provide support to those who feel the need to make the most important first step: to embark on this learning journey.

We organized the journey in three stages. The first part addresses the question: How is the field of customer insights being transformed? First, Einhorn and Löffler from Porsche illustrate the transformation process and highlight the importance of dynamic capabilities, particularly in the automotive industry. Then, Picareta, Weissheim, and Klöhn from Salesforce show how intelligent applications have become a crucial factor for success in modern sales organizations. Next, Neudecker et al. from Kantar look at how new technologies such as voice and facial coding can contribute to a better understanding of customer emotions. Guedes, Akinwale, and Fontecha from Credit Suisse provide an overview on how machine-driven content marketing can assist in targeting customers in the banking industry. Finally, Ottawa from Deutsche Telekom highlights the emergence of $5 \mathrm{G}$ and its importance in collecting customer data.

The second part of the book explores the question: Which analytical tools can generate customer insights? First, Lantz from the University of Michigan provides an overview of analytical tools that can be applied to gain customer insights. Then, Wang, Czerminski, and Jamieson from Harvard University explain some of the key features of deep neural networks and aspects of their design and architecture. Next, Hartmann from the University of Hamburg showcases how the power of decision tree ensembles can be harnessed based on a practical use case. Kwartler from Harvard Extension School distinguishes and defines text analytics and natural language processing and shows their value-adding practical application. Finally, Hofstetter from the University of Lucerne presents a concise six-step data scraping process to exploit the business value of online data.

The third part of the book explores the question: How can the management of customer insights lead to success? First, Jakobi, von Grafenstein, and Schildhauer from Humboldt University of Berlin argue that a well-designed privacy and data protection process is a key element for customer experience management. Then, Temkin from Qualtrics explores how success in the experience economy can be guaranteed by utilizing experience data. Next, Khan from SAP examines the data value equation and shows how it can generate business value. Zimmermann from the University of St. Gallen provides an overview of competition data science platforms and assesses their business potential. Blache et al. from Deutsche Bank introduce the KontoSensor as a tool for processing data which creates value for both businesses and customers. Finally, Frank from Ted Frank Strategic Story Consulting shows how applying story telling techniques contributes to a better understanding of data.

The machine age of customer insight is not only an exciting era of its own - it is also a key element for transforming customer insights into business value. This book affirms everyone who considers this era as a great opportunity while hopefully convincing those who are still skeptical. 
Part 1

Transformation 
This page intentionally left blank 


\title{
Chapter 1
}

\section{Transformation of Customer Insights}

Martin Einhorn ${ }^{1}$ and Michael Löffler ${ }^{2}$

\begin{abstract}
Digitalization is changing the assets, competencies, and value creation of the customer insight function. New data sources, methods, and technologies provide an unprecedented wealth of data and opportunity for efficiency. At the same time, it is leading to an evolution in necessary capabilities such as data synthesis, networking, and constant learning. Changes in the means of value creation have included automation of insights, more frequent evaluation of business results, and more emotional inspiration. Customer insights in the machine age drive customer centricity and go beyond the descriptive research function of previous "market research" within companies.
\end{abstract}

Keywords: Customer insights; market research; customer centricity; dynamic capabilities; data synthesis; customer insights automation

\section{Customer Centricity as a Driver for the Growing Importance of Customer Insights}

Digitalization is transforming customer insights as an industry and as a function within companies. This transformation is more than just the change from paper and pencil questionnaires to handheld devices or from time-consuming factor analysis on slow mainframe computers to the instant calculation on laptops. The transformation into the

\footnotetext{
${ }^{1}$ Dr. Martin Einhorn has been leading the customer insight function of Porsche for more than 10 years. He teaches customer insights at Sigmund Freud University Vienna. Previously, he worked as market and trend researcher with Audi AG and did several market research projects for large retailers during his doctoral thesis at the University of St. Gallen. He studied management in Leipzig and Marseille. ${ }^{2}$ Prof. Dr. Michael Löffler is Vice President Sales Planning \& Strategy at Porsche. Before assuming this role in 2018, he held various positions at Porsche, most recently as Vice President Customer Relations and Head of Marketing Planning. In addition, he has extensive and sound experience in the branded goods and consumer goods sector with a focus on consumer behavior and marketing strategy.
} 
machine age of customer insight is changing assets, competencies, and the means of value creation. The following contribution shows the transformation of customer insights through the example of another industry in digital transformation: the car industry. The case of Porsche customer insights illustrates the opportunities and challenges of this development perfectly, because the company has been known for customer centric products and services for many years.

Customer centricity is a key factor for success in saturated markets, service, and consumer goods industries (Morgan/Vorhies, 2018). Customer insights are considered a key driver for the development of customer centricity. The scientific findings coincide with Porsche's internal experience, which shows that customer information is the starting point for customer centricity. Growing customer centricity as part of corporate culture in turn leads to a growing and changing need for customer information in order to increase responsiveness (Hult, Ketchen, \& Slater, 2005) and innovative strength (Mahmoud, Blankson, Owusu-Frimpong, Nwankwo, \& Trang, 2016). The customer centricity of sustainably successful companies will further increase the overall demand for customer insights, even if this is not followed by proportionally higher budgets.

A further driver in the demand for customer insights is the changing organization of work. This has been prompted by design thinking methods (Brown \& Martin, 2015; Plattner et al., 2014) and user and use-oriented development processes for digital products (Brenner et al., 2014) that require even more frequent information about customer needs. The regular sharing of experiences and the topics of discussion at formal and informal meetings of international market research leaders confirm the core trend of growing demand for customer insights with nonproportional growth of resources.

An opportunity and also the fuel for a growing range of customer insights lies in the rapidly growing amount of available customer and behavioral data. The growth rate (CAGR) of global IP traffic is an indicator of the quantitative growth of data. Cisco (2019) puts it at $26 \%$ p.a. [?] from 2017 to 2022. According to this, IP traffic worldwide will increase from 120 ExaBytes to 396 ExaBytes per month. This forecast takes into account the increasing number of Internet-enabled devices in households, which will rise from a global average of 2.4 per household in 2017 to 3.6 by 2022. The highest equipment ratio is already 8.0 in North America and will continue to rise to 13.4 devices. To make it more tangible: $94 \%-98 \%$ of the population in many European and North American countries have a smartphone or a mobile phone. Among young people, it is even more (Pewresearch, 2019). Google receives 3.5 billion search queries per day (internetlivestats); this is about one query for every second person; 3.2 billion users use at least one Facebook service per month (Allfacebook.de, 2020). In 2019 alone, 305 million wearables were sold worldwide (Statista, 2020). For the readers of this book it will be harder to find someone in their circle of acquaintances who does not have a smartphone, has not searched on Google in the last month, and does not have any other smart device than someone who participated in a phone survey last month.

The growing amount and diversity of digital data as a resource is leading to far-reaching changes in the fundamental function and processes of customer insights departments in companies and providers in the marketplace, which previously saw themselves as the "producers" of "customer information" resources. This growth in data volume and 
diversity, coupled with the growth in the number of data-generating devices, justifies the term "machine age" for customer insights.

The changes in the customer insight industry are reflected in the new players along the entire value chain, from data generation, processing, and analysis to visualization. This can be seen in new technologies and customer insight consulting methods (GRIT Report, 2019, p. 64) but also in the complete transformation of individual value chains through automation and data privacy requirements (see Jakobi et al., Chapter 11).

\section{The Transformation from Market Research to Customer Insights}

Standard works on market research often portray the market research process as essentially complete after data collection and evaluation (e.g., Esch, Herrmann, \& Sattler, 2013, p. 91; Koch, Riedmüller, \& Gebhardt, 2016, p. 11). The ESOMAR definition from 2009 also understands market research as

... the systematic gathering and interpretation of information about individuals or organizations using the statistical and analytical methods and techniques of the applied social sciences to gain insight or support decision making. The identity of respondents will not be revealed to the user of the information without explicit consent and no sales approach will be made to them as a direct result of their having provided information.

In the 5th edition of their standard work in 2017, Malhotra, Birks, and Nunan (2017, p. 7) already placed more emphasis on the function of market research as a link between customers and decision-makers than on data acquisition. According to them, market research

... is the function that links the consumer, customer, and the public to the marketer through information - information is used to identify and define marketing opportunities and problems; generate, refine, and evaluate marketing actions; monitor marketing performance; and improve understanding of marketing as a process. Marketing research specifies the information required to address these issues, designs the method ... and communicates the findings and their implications. (Malhotra et al. 2017, p. 7)

In practice, however, former market research departments are increasingly expected to provide decision support - right up to helping to shape business strategies (e.g., Young \& Javalgi, 2007, p. 116). This also includes the adequate communication of results. Pure reporting has long since been replaced by "telling the research story" specific to the target and addressee (Smith \& Fletcher, 2004, p. 1). In some cases, the role of market research even includes the implementation of market research results and translation into action plans (e.g., Xu, 2005, p. 21). The market researcher is tasked with and expected to be able to "spot how research can solve a problem and help a firm make better decisions" (Proctor, 2005, p. 28). This shows that the transformation of the customer research function started several years ago.

The new understanding goes beyond the understanding of "research" as an information provider. It focuses on the generation of "insights." Insights include their own value creation and also require meta-knowledge of the suitability of data sources, tools, and 
process alternatives based on rapidly changing assets such as data sources and tools. The frequently named "customer" insights department usually includes potential customers and thus eliminates the need to discuss "customer" or "consumer."

\section{Dynamic Capabilities as Necessity and Opportunity}

The rapidly changing assets and competencies in the customer insights machine age require dynamic capabilities in order to generate value for companies. Teece, Pisano, and Shuen (1997, p. 516) define dynamic capabilities as the ability of companies and parts of companies to combine and adapt competencies ("ability to build, integrate, and reconfigure internal and external competencies to address rapidly changing environments"). In doing so, they pay particular attention to assets such as technologies and processes (Teece et al., 1997, p. 519). In a comprehensive review of numerous publications, Eloranta and Turunen (2015, p. 397) highlight the role of technologies, tools, learning processes, and internal service networks in promoting dynamic capabilities. Eloranta and Turunen's research also shows that dynamic capabilities are particularly necessary in the transition from product-driven to service-infused organizations (p. 412) and that a network-like organization of resources and technologies supports dynamic capabilities.

The GreenBook Research Industry Trends Report (GRIT Report) surveys the topics and focal points of the customer insight industry among customers and providers on a quarterly basis. It was significantly altered in 2019 and renamed GRIT Business \& Innovation Report with the goal of generating more value and impact (p. 3). In terms of content, the GRIT Business \& Innovation Report, 2019; see Fig. 1.1 clearly shows which competencies and assets are currently most important in the industry: AI, automation, machine learning, and big data analytics. On the buyer side, methods, data integration, real-time reporting, and storytelling are just as important as automation.

This shows a stabilization of the trends that were already apparent in the GRIT Report (2018). Big data, diverse data sources, tools for automated data processing, and AI are

Fig. 1.1. Customer Insight Industry Opportunities and Challenges.

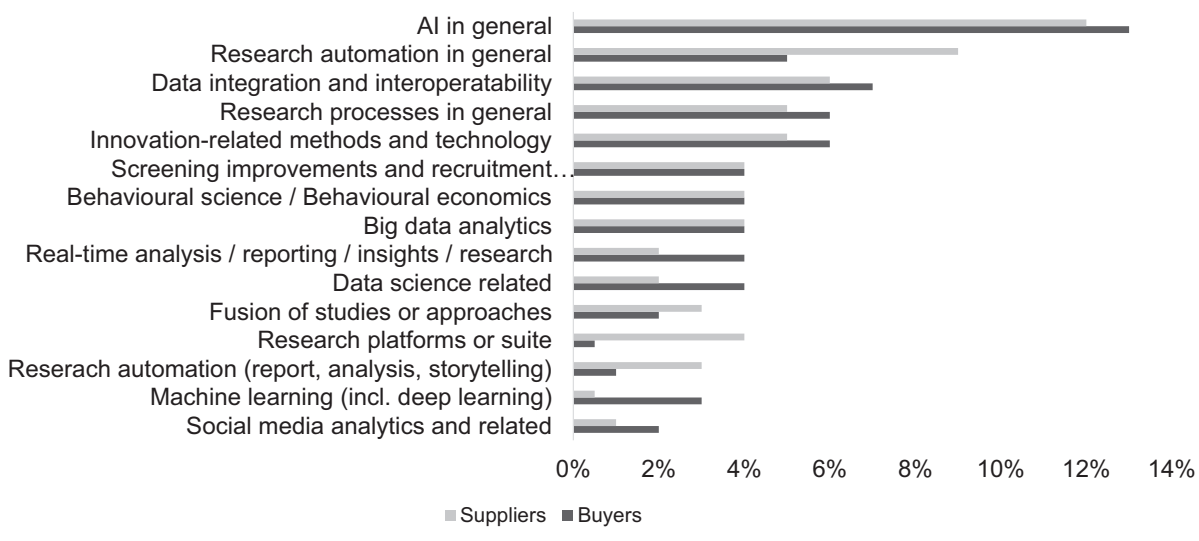

